\title{
Ibuprofen Release from Hydrotalcite-like Materials Filled into Chitosan/Alginate Composites as Promising Reabsorbable Membranes
}

\author{
Monielly Viomar Machado ${ }^{a}$ (), Silvia Jaerger ${ }^{a *}$ (), Leandro Zattab, Marins Danczuk ${ }^{a}$, \\ Rafael Marangoni ${ }^{a}$ \\ ${ }^{a}$ Universidade Estadual do Centro-Oeste, Departamento de Química, 85040-167, Guarapuava, PR,
Brasil. \\ ${ }^{b}$ Universidade Tecnológica Federal do Paraná, Departamento de Química, 85503-390, Pato Branco, \\ PR, Brasil.
}

Received: June 26, 2021; Revised: October 14, 2021; Accepted: November 29, 2021

\begin{abstract}
Hydrotalcite-type materials, or layered double hydroxide (LDH), are very promising in applying slow-release drug systems through ion exchange and delamination characteristics at acidic $\mathrm{pH}$. In this paper, $\mathrm{Zn} / \mathrm{Al} \mathrm{LDHs}$ in 2:1 and 3:1 molar ratios intercalated with the drug ibuprofen (IBU) were added to chitosan/alginate membranes. In the release tests, an increase in the solubility of the drug in the membranes could be observed, and the percentage of drug release is lower than the percentage of drug release in the free samples. The following release percentages were obtained: $15.48 \%$ and $17.5 \%$ of the drug in water, and $23.22 \%$ and $26.25 \%$ of the drug in PBS buffer solution, respectively, for membrane samples containing $\mathrm{Zn}_{2} \mathrm{Al}-\mathrm{IBU}$ and $\mathrm{Zn}_{3} \mathrm{Al}-\mathrm{IBU}$ LDHs. Thus, the synthesized hybrid membranes (chitosan/alginate-LDH-IBU) are promising in the application as resorbable membranes for bone grafting with drug release.
\end{abstract}

Keywords: layered double hydroxide, alginate, chitosan, drug release.

\section{Introduction}

There are several clinical reasons for developing bone materials in the reconstruction of defects, including the need for bone implants in dentistry that are most suitable for the biological environment. Traditional methods for treating these defects generally include autologous grafts (from the same patient), homologous grafts (from other individuals of the same species), and xenogenic grafts (from individuals of different species - e.g., bovine). Traditional methods for repairing such defects can be inefficient since bone grafts are avascular and diffusion dependent, and bone resorption is unpredictable since graft can be reabsorbed by the patient's body before osteogenesis is completed ${ }^{1-3}$. Another critical factor that limits the use of these grafts is the defect size because donor tissue is often scarce, making the procedure expensive, and significant local morbidity may occur. In addition, it can often be associated with pain, infection, and bruising, which can cause a decrease or total loss of bone growth inducing factors ${ }^{4-6}$.

Through this problem, bone substitutes have been studied, having improved physical, chemical, and mechanical properties than the currently used and without the need for a donor site. These alternative materials can be ceramic, polymeric, metallic, and composites called alloplastic grafts. Therefore, bone tissue engineering seeks a material that functions as a scaffold (acellular matrix), biocompatible, bioresorbable, and which induces bone formation from the

*e-mail: sjaerger@gmail.com surrounding tissue, still acting as a carrier or a model for bone cells in the deficient location ${ }^{7-10}$.

In addition to biocompatibility and bone regeneration, another need is found in the control of postoperative pain in extensive bone graft surgeries, accentuating in the area of dentistry, and the pain problem is more significant than in other medical specialties ${ }^{11}$.

As a cause of this type of orofacial pain, there is the primary periodontal inflammatory reaction due to surgical trauma in the periapical region, where the pain can be continuous and pulsating for a prolonged time, usually together with the formation of abscesses and pyrexia. Pain, as well as the inflammatory process and pyrexia, are important biological phenomena in defense of the organism, and considered typical in any surgical case. However, uncomfortable for the affected individual and with possible development of pathologies, requiring symptomatic therapy using non-opioid analgesic drugs (NSAIDs - non-steroidal anti-inflammatory drugs) - such as ibuprofen - and in some situations, associated with opioids ${ }^{12,13}$.

Generally, these drugs are prescribed for oral administration, but in post-surgical cases, there is a need for administration in several daily doses to relieve symptoms. Due to the high doses, side effects such as gastric problems can occur, which can aggravate ulcers. In addition, these prothrombotic problems can conduct to cardiovascular problems, resulting from the continuous use of these drugs ${ }^{14-16}$.

All of these factors outlined the research to develop controlled release systems for drugs, refining their transport system, counting with different synthesis methods and matrix processes that were able to allow the release of active principles 
a predetermined rate over a period of time pre-established, its behavior being dependent on the environment in which it is administered. In addition, this method requires less administration, presenting a constant plasma concentration of the drug, decreasing the levels of toxicity that are common in traditional administration methods ${ }^{16,17}$.

Several systems for controlled drug release have been studied and described, comparing their advantages and disadvantages and being classified into four main groups: viral carriers, organic cationic compounds, recombinant proteins, and inorganic nanoparticles. The layered double hydroxides (LDHs) can fit in the group of inorganic nanoparticles, and chitosan is promising in this area since they have low toxicity, biocompatibility, and also highly promising for promoting the controlled/slow release of drugs (which may be non-steroidal anti-inflammatory drugs). The controlled/ slow release of drugs intercalated in LDHs occurs due to the dissolution of the matrix in the function of layer etching or an anionic exchange reaction. For the chitosan, the drug release is attributed to its primary amine functional group ${ }^{18-23}$.

LDHs belong to the class of anionic clays, and their structure is derived from brucite, $\mathrm{Mg}(\mathrm{OH})_{2}$. Thus, the metallic atoms are coordinated with hydroxyls in an octahedral site, forming an infinite two-dimensional layer structure. When the divalent metal atoms $\left(\mathrm{M}^{2+}\right)$ are partially replaced by trivalent metals $\left(\mathrm{M}^{3+}\right)$, a positive charge residue is formed on the layer, requiring anions in the interlayer space to neutralize the charges. These materials are called layered double hydroxides and can be synthesized in laboratory ${ }^{24}$.

Recent studies discuss the application of LDH in bone tissue applications. Among them stands out the research of Wang et al. ${ }^{25}$, where the authors synthesized MgAl-layered double hydroxide (LDH) microsheets modified PMMA (PMMA\&LDH) bone cement with superior osseointegration performance. Results show that in vivo assays PMMA\&LDH has been demonstrated superior osteogenic ability, which boosts bone growth by 2.17 - and 18.34-fold increments compared to other groups without LDH at 2 months, postoperatively ${ }^{25}$. In a similar study, Liu et al. ${ }^{26}$ fabricated an integrated strategy involving mesenchymal stem cells (MSCs) recruitment, and multifunctional therapeutic biomaterials of bone regeneration and vascularization containing a bilayer peptide-loaded scaffold consisting of CK2.1 coated $\beta$-glycerophosphate/ chitosan (CK2.1@GC) for cartilage regeneration and LL37 modified layered double hydroxide/chitosan (LL37@LC) for subchondral bone regeneration ${ }^{26}$. Drug-loaded-LDHs incorporated in biopolymers as composite for bone tissue application are also recently investigated. Shokrolahi et al. ${ }^{27}$ prepared drug-loaded-LDH/PLGA composites via electrospinning to afford a bioactive/osteoinductive scaffold. Assays by alkaline phosphatase activity and Alizarin Red staining indicated that the scaffold with 5\% drug-loadedLDH (Mn-Mg-LDH/PLGA/AT5\%) induced a remarkably higher level of the markers compared to the PLGA scaffold ${ }^{27}$. In the Kim et al. ${ }^{28}$ study, a bioabsorbable polymeric bone plate was proposed to be enabled with both diagnostic and therapeutic functionalities. This study investigated a druginorganic nanohybrid (RS-LDH) where an anti-resorptive bone remodeling drug was intercalated into a layered double hydroxide (LDH) via an ion-exchange reaction.
The RS-LDH was added in poly(lactic-co-glycolic acid), a biodegradable polymer, and the results show a clinically approved bioabsorbable bone plate to produce the theranostic plate $^{28}$. However, a study using Zn/Al LDH with different molar ratios intercalated with ibuprofen in chitosan and alginate films to bone treatment is rare.

Thus, this work aims to design a chitosan/alginate membrane filled with ibuprofen intercalated in the LDH structure. The intercalation of this drug provides its slow release at the insertion site of the alloplastic graft and the dispersion of this LDH in a hybrid membrane composed with chitosan, responsible for promoting bone regeneration of the deficient site. Combining greater effectiveness in controlling postoperative symptoms with faster bone regeneration, this hybrid membrane may promote a quicker recovery in surgical cases of bone grafts.

\section{Experimental}

\subsection{Materials}

For the synthesis of LDHs and hybrid membranes, as well as for carrying out in vitro release tests, the following reagents were used: aluminum nitrate nonahydrate P.A. (Neon), zinc nitrate hexahydrate P.A. (Synth), micro pearl sodium hydroxide P.A. (Neon), low viscosity sodium alginate (Vetec), Hydrochloric Acid P.A. (Anhydrol), glutaraldehyde 25\% P.S. solution (Alphatec), ethylene glycol P.A. (Dynamic), sodium bicarbonate P.A. (Neon), monobasic potassium phosphate anhydrous P.A. (Neon), potassium chloride P.A. (Neon), Ibuprofen (Fagron)* and high-density chitosan (Galena)* (*: pharmacological grade reagents).

\subsection{Synthesis of layered double hydroxides intercalated with ibuprofenate}

LDHs were synthesized by the co-precipitation method at constant $\mathrm{pH}$, according to a procedure described elsewhere ${ }^{24}$, which consists of the simultaneous and slow addition of two solutions. The first solution contains the nitrates salts of the $\mathrm{Zn}^{2+}$ and $\mathrm{Al}^{3+}$ (with ratios 2:1 and 3:1), and the second solution contains $\mathrm{NaOH}\left(0.5 \mathrm{~mol} \mathrm{~L}^{-1}\right)$. Both were added into a reactional vessel containing a solution with the ibuprofen salt (the amount of the ibuprofen salt corresponds to 4 times the anion exchange capacity of LDH). The addition was carried out at constant $\mathrm{pH}$ at $8.5 \pm 0.5$, with vigorous stirring of the solution.

The materials precipitated were kept in contact with the reaction medium for approximately 72 hours. Then, the resulting materials were centrifuged at $3500 \mathrm{rpm}$ and washed five times with ultrapure water. Finally, the materials were dried at around $50{ }^{\circ} \mathrm{C}$ for 24 hours, pulverized, and stored away from heat and humidity. The synthesized LDHs were denominated $\mathrm{Zn}_{2} \mathrm{Al}-\mathrm{IBU}$ and $\mathrm{Zn}_{3} \mathrm{Al}-\mathrm{IBU}$.

\subsection{Preparation of membranes chitosan/alginate}

To prepare the membranes (Figure S1 (supplementary material), $0.5 \mathrm{~g}$ of chitosan was dispersed in $100 \mathrm{~mL}$ of an $\mathrm{HCl}$ solution $\left(0.1 \mathrm{~mol} \mathrm{~L}^{-1}\right)$ in a proportion of $0.5 \%(\mathrm{wt} / \mathrm{vol})$. The flask was sealed and stirred for 24 hours, and then the solution was centrifuged at $3500 \mathrm{rpm}$ for 15 minutes to 
remove possible contaminants and insolubilized chitosan (step 1, Figure S1).

The prepared chitosan solution, after this time, was added in $90 \mathrm{ml}$ of sodium alginate solution $(5 \% \mathrm{wt} / \mathrm{vol})$. And then, $75.50 \mu \mathrm{l}$ of glutaraldehyde (4\% wt/wt - cross-linking agent) and $0.11 \mathrm{ml}$ of ethylene glycol $(25 \% \mathrm{wt} / \mathrm{wt}$ - plasticizer $)$ were added to the flask. The amount of cross-linking agent and plasticizer were calculated in relation to the dry chitosan mass. Next, the system was kept under magnetic stirring for 24 hours at $55^{\circ} \mathrm{C}$ in a hermetically sealed flask (step 2).

Subsequently, the membrane obtained was immersed in $25 \mathrm{~mL}$ of the glutaraldehyde solution (4\% wt/wt) for $1 \mathrm{~h}$ to cross-link the alginate and chitosan chains that eventually were still free. To remove the excess crosslinker, two more immersions were performed in $25 \mathrm{~mL}$ of ultrapure water for 30 minutes each, and the neutralization of the acid in the membranes was performed by immersion in $25 \mathrm{~mL}$ of sodium bicarbonate $\left(0.1 \mathrm{~mol} \mathrm{~L}^{-1}\right)$ (step 3 , Figure $\left.\mathrm{S} 1\right)$. The final drying was carried out at room temperature for 24 hours, and the samples were appropriately stored (protected from heat and humidity).

\subsection{Preparation of membranes chitosan/alginate/ $L D H-I B U$}

For the synthesis of the membranes filled with LDH/ IBU, right after step 2, $6 \mathrm{mg}$ of the LDHs $\left(\mathrm{Zn}_{2} \mathrm{Al}-\mathrm{IBU}\right.$ or $\mathrm{Zn}_{3} \mathrm{Al}$-IBU) were added in $25 \mathrm{~mL}$ of the chitosan/alginate solution (step 3, Figure S1). The system was kept under magnetic stirring for $24 \mathrm{~h}$, to improve the homogeneity of LDH particles with the polymer blend. Then, the mixture was transferred to Petri dishes and dried at $40{ }^{\circ} \mathrm{C}$ for 24 hours, and then, the step 3 of item 2.3 with the membranes obtained.

The hybrid membranes that passed through the immersion processes and did not contain the LDHs were named HM, the membranes that contained only ibuprofen were named $\mathrm{HM} / \mathrm{IBU}$, and the membranes that contained the synthesized $\mathrm{LDH}$ were named $\mathrm{HM} / \mathrm{Zn}_{2} \mathrm{Al}-\mathrm{IBU}$ and $\mathrm{HM} / \mathrm{Zn}_{3} \mathrm{Al}-\mathrm{IBU}$.

\subsection{Measurement of in vitro release}

For the study of in vitro release, initially, the analytical curves for the solubilized ibuprofenate were made in the media in which the release tests were carried out (water and in PBS solution). The analytical curves were performed in triplicates starting from a stock solution $\left(1 \mathrm{~g} \mathrm{~L}^{-1}\right)$ and diluting to concentrations of 0.001 to $0.01 \mathrm{~g} \mathrm{~L}^{-1}$.

Each sample was added separately in $800 \mathrm{~mL}$ of solution (release medium: water and $\mathrm{PBS}$ solution with $\mathrm{pH}=7.4$ - blood $\mathrm{pH})$, maintaining constant magnetic stirring from 200 to 500 $\mathrm{rpm}$ and temperature of $36.5 \sim 37^{\circ} \mathrm{C}$ (body temperature). The volume of the solution was greater than $3 \mathrm{x}$ the saturation point of the substance (Ibuprofen) and within the range of 500 to $1000 \mathrm{~mL}$, under Sink condition and concentration of free samples and samples contained in the membranes were $0.0075 \mathrm{~g} \mathrm{~L}^{-1}$, so that the diameters of the membranes were $6 \mathrm{~cm}$ and thickness $0.03 \mathrm{~cm}$.

Aliquots of $5 \mathrm{~mL}$ were taken from each sample every $10 \mathrm{~min}$ for 1 hour of experiment, followed by aliquots every 30 minutes for 3 hours of experiment, every 1 hour for 6 hours of experiment, every 12 hours up to 24 hours of experiment, and every 24 hours up to 168 hours ( 7 days or 10080 minutes) of experiment. All withdrawn rates were duly replaced in their respective bottles.

The tests were performed in triplicates, and the aliquots were analyzed by UV-Visible Spectroscopy with maximum $\lambda=222 \mathrm{~nm}$ (Ibuprofen) and scanning range from 300 to $190 \mathrm{~nm}$ to determine the quantities of the drug released into the medium.

\subsection{Material characterization}

The structure of the materials was studied with X-ray powder diffraction measurements performed in a Bruker Diffractometer, D2 Phaser, using $\mathrm{CuK}_{\alpha}$ radiation source $(\lambda=1.5418 \AA), 30 \mathrm{~mA}$ and $40 \mathrm{kV}$, range of 3 to $70^{\circ} 2 \theta$, a step of $0.05^{\circ} \mathrm{min}^{-1}$ and rotation of $5 \mathrm{rpm}$.

The UV-Visible spectra were obtained in a Shimadzu spectrophotometer, model UV-1800, with $20 \mathrm{~W}$ halogen and deuterium sources and a photodiode silicon detector. The spectra were collected in the wavelength range of 180-250 nm and monitored the band at $222 \mathrm{~nm}$.

Infrared spectra with Fourier transform (FTIR) were collected in a Perkin Elmer Frontier spectrophotometer in the transmission mode in the range from 4000 to $400 \mathrm{~cm}^{-1}$ with a resolution of $4 \mathrm{~cm}^{-1}$ and an accumulation of 32 scans. The analyzes were performed using $\mathrm{KBr}$ tablets containing $1 \mathrm{wt} \%$ of the samples.

To the thermogravimetric analysis, a simultaneous thermogravimetric Thermal Analyzer (TGA) and DSC differential thermal analysis, equipment from SEIKO TG/DSC 6300, under dynamic atmosphere heating rate $10{ }^{\circ} \mathrm{Cmin}^{-1}$; Pt sample support. The experiments were carried out from room temperature to $1000{ }^{\circ} \mathrm{C}$.

The Energy Dispersive X-ray spectroscopy (EDS) aims to obtain the chemical composition of LDHs. The microanalyses were obtained using the SwiftED 3000 Energy Dispersive X-ray Spectrometer coupled to a Hitachi TM-3000 scanning electron microscope.

\section{Results and Discussion}

\subsection{LDHs characterization}

$\mathrm{Zn} / \mathrm{Al} \mathrm{LDHs}$ composition were chosen because of the biocompatibility of these metals, which, when inserted in the organism, do not cause a rejection response $\mathrm{e}^{29-31}$. The choice of the ratio of these metals in the layered structure is due to the fact that the $2: 1$ and $3: 1$ ratio are the most easily obtained, and this variation of the ratios promotes different amounts of the anions that can be intercalated.

The X-Ray Diffractograms of the LDHs Zn/Al intercalated with ibuprofen are presented in Figure 1. The peaks represented by the planes (003) and (006) for LDHs (Figure 1b and 1c) are a series of basal reflections obtained at the low degree (2 $\theta)$ and allow the direct determination of the basal spacing, which is equal to the distance of a layer similar to the brucite plus the space occupied by the intercalated anion. Since the most common polytype for this $\mathrm{LDH}$ is the $3 \mathrm{R}$ polytype, the unit cell parameter is $\mathrm{c}=3 \mathrm{~d}$, and the reflection of the lowest angle is indexed as (003) even if the spacing corresponds to the value of $d$. 


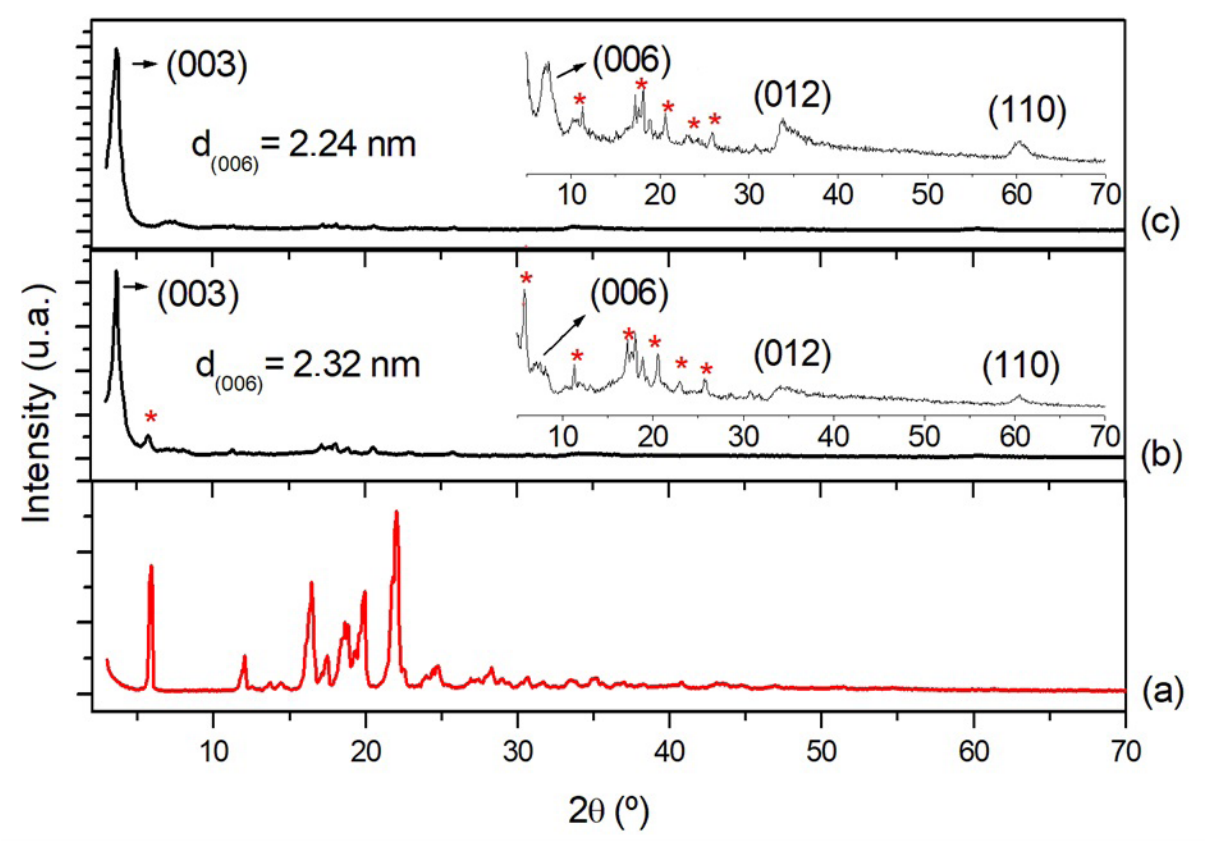

Figure 1. X-ray diffraction patterns of (a) Ibuprofen, (b) $\mathrm{Zn}_{2} \mathrm{Al}-\mathrm{IBU}$ and (c) $\mathrm{Zn}_{3} \mathrm{Al}-\mathrm{IBU}$.

Thus, the value obtained for the basal spacing of the $\mathrm{Zn}_{2} \mathrm{Al}-\mathrm{IBU}$ and $\mathrm{Zn}_{3} \mathrm{Al}-\mathrm{IBU}$ was 2.24 and $2.32 \mathrm{~nm}$, respectively (using the highest order basal peak (006)). The value was found through the Bragg equation (Equation 1).

$$
2 d \operatorname{sen} \theta=n \lambda, \lambda=0.15418 \mathrm{~nm}
$$

These $\mathrm{d}$ values propose that ibuprofen is in the form of a bi-layer in the interlayer space, with the carboxyl groups oriented in the direction of the layers, serving as a pillar between the layers (Figure 2). As the synthesis method used was that of co-precipitation at constant $\mathrm{pH}$, besides the drug and water molecules, there is also the existence of anion nitrate in the interlayer space, which is the source of starting salts ${ }^{32,33}$. However, other characteristic reflections of these materials were observed, particularly the diffraction plane (012) in intermediate values of angles at $2 \theta$, which is related to the stacking pattern of the layers indicating a $3 \mathrm{R}$ polytype, where the parameter $c$ was 6.72 and $6.96 \mathrm{~nm}$ for the $\mathrm{Zn}_{2} \mathrm{Al}-\mathrm{IBU}$ and $\mathrm{Zn}_{3} \mathrm{Al}-\mathrm{IBU}^{33,34}$.

The diffraction plane (110) and (113) in high angle (approximately $60^{\circ}$ in $2 \theta$ ) that in some cases the diffraction plane (110) is well defined and correspond to the distance between two metallic cations, being possible to calculate the value for parameter $a$, where $\mathrm{a}=2 \mathrm{~d}_{(110)}$. Then obtaining the value of $a$ of approximately $0.306 \mathrm{~nm}$ for the $\mathrm{Zn}_{2} \mathrm{Al}-\mathrm{IBU}$ and $0,307 \mathrm{~nm}$ for the $\mathrm{Zn}_{3} \mathrm{Al}-\mathrm{IBU}$.

The infrared spectra of Ibuprofen and LDHs derivated of ibuprofen are shown in Figure 3. The band centered at $3357 \mathrm{~cm}^{-1}$ of LDHs is associated with the stretch of O-H bond present in the structure of layers and the water molecules present in the materials. This $\mathrm{O}-\mathrm{H}$ stretching mode is associated with the LDH layers structure and indicates that $\mathrm{OH}$ groups of the layers are interacting with the ibuprofen through of hydrogen bond.
Bands in the region of 3000 to $2800 \mathrm{~cm}^{-1}$ are related to stretching of aliphatic $\mathrm{C}-\mathrm{H}$ bonds present in the anion Ibuprofenate which is intercalated. At $1569 \mathrm{~cm}^{-1}$, they are characteristic stretching bands of the $\mathrm{C}=\mathrm{C}$ bonds of the aromatic ring and $\mathrm{C}=\mathrm{O}$ bonds of the carboxylic acid grouping of ibuprofen. The band in the $1406 \mathrm{~cm}^{-1}$ region is characteristic of the $\mathrm{N}-\mathrm{O}$ connection, indicating that the nitrate anion $\left(\mathrm{NO}_{3}^{-}\right)$is also intercalated in the interlayer space of these materials.

The region between 1252 to $733 \mathrm{~cm}^{-1}$ is relative to the elongation of $\mathrm{C}-\mathrm{O}$ bond and bend deformations of $\mathrm{C}-\mathrm{H}$ aromatic rings bonds and the $\mathrm{O}-\mathrm{H}$ bonds. And, the bands below $700 \mathrm{~cm}^{-1}$ can be interpreted as vibration modes of the layer network, such as $\mathrm{M}-\mathrm{OH}$ and O-M-O stretching vibrations ${ }^{34}$. All vibrational modes observed in Figure 3 are summarized in Table S1 (supplementary material).

The thermal behavior of the LDHs was studied employing the thermal analysis measurements (TGA/DSC), and their thermal decomposition profile of LDHs are presented in Figure 4. The generic reaction of thermal decomposition can be described as follows ${ }^{35}$ :

$$
\begin{aligned}
& {\left[\mathrm{Zn}_{1-x} \mathrm{Al}_{x}(\mathrm{OH})_{2}\right]\left(\mathrm{C}_{13} \mathrm{H}_{17} \mathrm{O}_{2}\right)_{z} \cdot y \mathrm{H}_{2} \mathrm{O}_{(s)} \stackrel{>500^{\circ} \mathrm{C}}{\rightarrow} x / 2 \mathrm{ZnAl}_{2} \mathrm{O}_{4(s)}+} \\
& (1-(3 x / 2)) \mathrm{ZnO}_{(s)}+(2 y+17 z+2) \cdot \mathrm{H}_{2} \mathrm{O}_{(g)}+13 \mathrm{CO}_{2}(\mathrm{~g})
\end{aligned}
$$

The TGA/DSC curve of the $\mathrm{Zn}_{2} \mathrm{Al}-\mathrm{IBU}$ and $\mathrm{Zn}_{3} \mathrm{Al}-\mathrm{IBU}$ (Figure 4) showed six main mass losses for both materials. The first event (endothermic) occurs from room temperature up to approximately $70{ }^{\circ} \mathrm{C}$ and is related to the elimination of water molecules adsorbed on the surface of the layer, presenting mass losses of 4.24 and $2.94 \%$. The second event (endothermic) that occurs at approximately $180{ }^{\circ} \mathrm{C}$ is due to the elimination of water molecules that are in the 


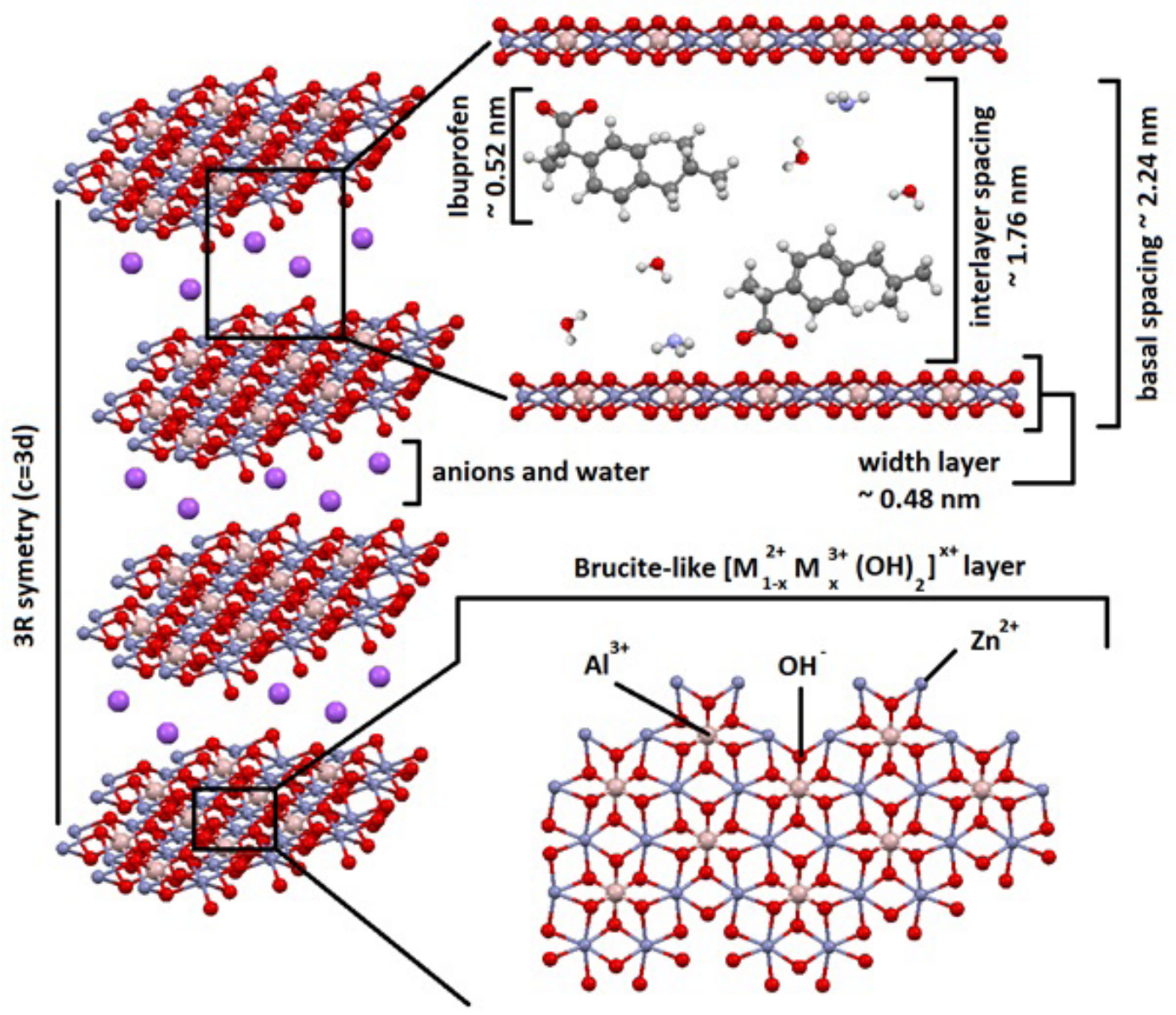

Figure 2. Schematic representation of the LDH structure of $\mathrm{Zn}_{2} \mathrm{Al}-\mathrm{IBU}$.

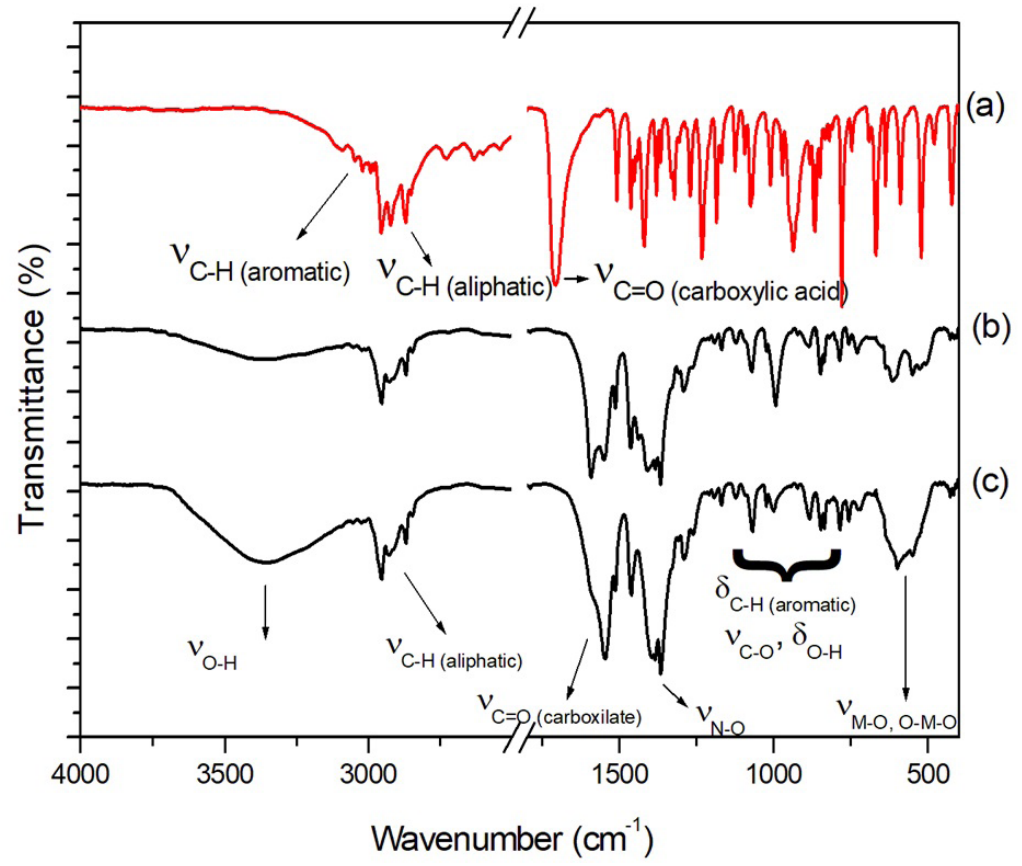

Figure 3. Infrared spectra for (a) Ibuprofen, (b) $\mathrm{Zn}_{2} \mathrm{Al}-\mathrm{IBU}$ e (c) $\mathrm{Zn}_{3} \mathrm{Al}-\mathrm{IBU}$. 


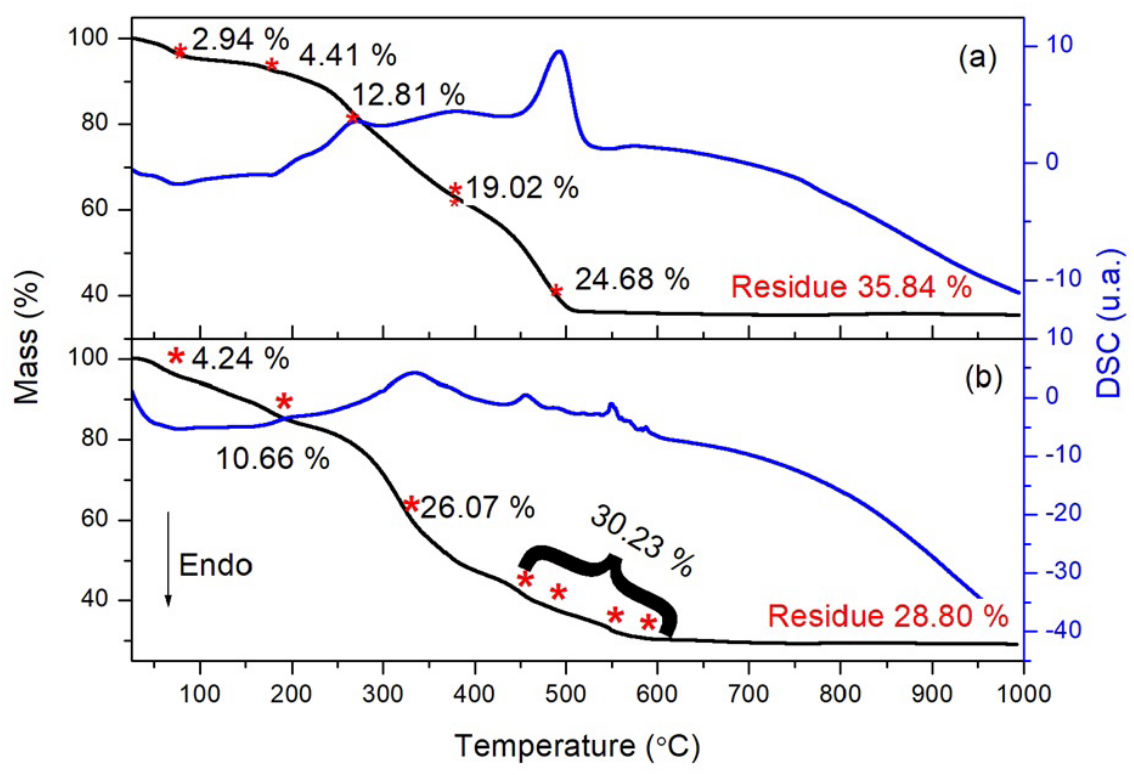

Figure 4. Thermal analysis curves (TGA and DSC) of LDHs $\mathrm{Zn}_{2} \mathrm{Al}-\mathrm{IBU}$ (a) and (b) $\mathrm{Zn}_{3} \mathrm{Al}-\mathrm{IBU}$.

interlayer space and linked to the layers through hydrogen bonds, presenting a loss of mass of $4.41 \%$.

The third event (exothermic) occurs at approximately $250{ }^{\circ} \mathrm{C}$ and is related to the dehydroxylation process of LDH structure, with mass losses of 10.66 and $12.81 \%$, respectively. The fourth event (exothermic) occurs at approximately $350{ }^{\circ} \mathrm{C}$ and is related to the elimination of the anion nitrate, which is intercalated, with mass losses of 26.07 and $19.02 \%$, respectively. The last event(exothermic) occurs at $450{ }^{\circ} \mathrm{C}$ and is related to the process of combustion of organic matter and consequent formation of oxides, with mass losses of 30.23 and $24.68 \%$. Moreover, at the end of the process, presenting 28.80 and $35.84 \%$ by mass of residue.

The EDS technique, coupled with the Scanning Electron Microscopy (SEM), confirms the ratio between divalent and trivalent metals, indicating atomic percentage values for $\mathrm{Zn}$ and Al metals. The chemical analysis module for the LDHs is presented in Table 1 .

With the results of TGA/DSC (percentage of $\mathrm{LDH}$ without water and percentage of waste) together with the results of EDS (atomic percentage of metals), it is possible to predict the general formula of the LDHs: $\left[\mathrm{Zn}_{0,67} \mathrm{Al}_{0,33}(\mathrm{OH})_{2}\right]$ $(\mathrm{IBU})_{0,485} \cdot 0,626 \mathrm{H}_{2} \mathrm{O}$ and $\left[\mathrm{Zn}_{0,75} \mathrm{Al}_{0,25}(\mathrm{OH})_{2}\right](\mathrm{IBU})_{0,658} \bullet 1,590 \mathrm{H}_{2} \mathrm{O}$.

\subsection{Membrane characterization}

The X-ray diffracts of the constituent polymers and membranes are shown in Figure 5. The chitosan diffraction peak was displaced (Figure 5A-b) to smaller angles in $2 \theta$ due to the reticulation of the polymeric chains of chitosan and alginate (Figure 5A-c), indicating that the polymeric aggregates formed have a preferential orientation.

When comparing the diffraction diagrams of chitosan/ alginate membranes with and without the addition of the cross-linker (Figure 5A-c and 5A-d) was possible to observe that with the presence of the cross-linker the union of the
Table 1. Chemical Analysis Module (EDS) for LDH.

\begin{tabular}{ccc}
\hline LDH-IBU Ratio & Zn (atomic \%) & Al (atomic \%) \\
\hline $2: 1$ & 67.2 & 32.8 \\
\hline $3: 1$ & 75.1 & 24.9
\end{tabular}

Atomic $\%$ is the average of 5 measurements taken at different points in the sample.

polymeric chains of chitosan with alginate is more ordered. This observation indicated by the increase in the intensity of the peak diffraction of the synthesized membranes.

This increase in ordering of polymeric network can also be observed in the images of the membranes obtained (Figure 5B and 5C). In Figure 5C, it is possible to observe a higher translucency in the obtained membrane when compared to the membrane of Figure 5B. This effect is related to the reticulation of the polymeric chains, which is responsible for the addition of the cross-linker in the immersion processes.

The ordering for polymers and polymeric membranes is generally in semi-crystalline to amorphous form, as most polymeric aggregates are randomly oriented, and this orientation can be improved by adding temperature to the cross-linked slab of polymeric chains and when the precursor polymers are of low density (low molecular weight).

In Figure 6, the X-ray diffractograms of the membranes containing Ibuprofen and the LDHs are shown. It is observed for the chitosan/alginate membrane containing only Ibuprofen (Figure 6A-d) characteristic peaks of the drug are indicated with *, initiating a little dispersion, and little interaction of the drug with the polymeric network formed and observed through the crystals of ibuprofen on the surface of the membrane (Figure 6C).

For hybrid membranes containing LDHs-IBU (Figure 6A-b and $6 \mathrm{~A}-\mathrm{c}$ ) is observed that there was an interaction between the polymeric network and the LDHs and that there is no 

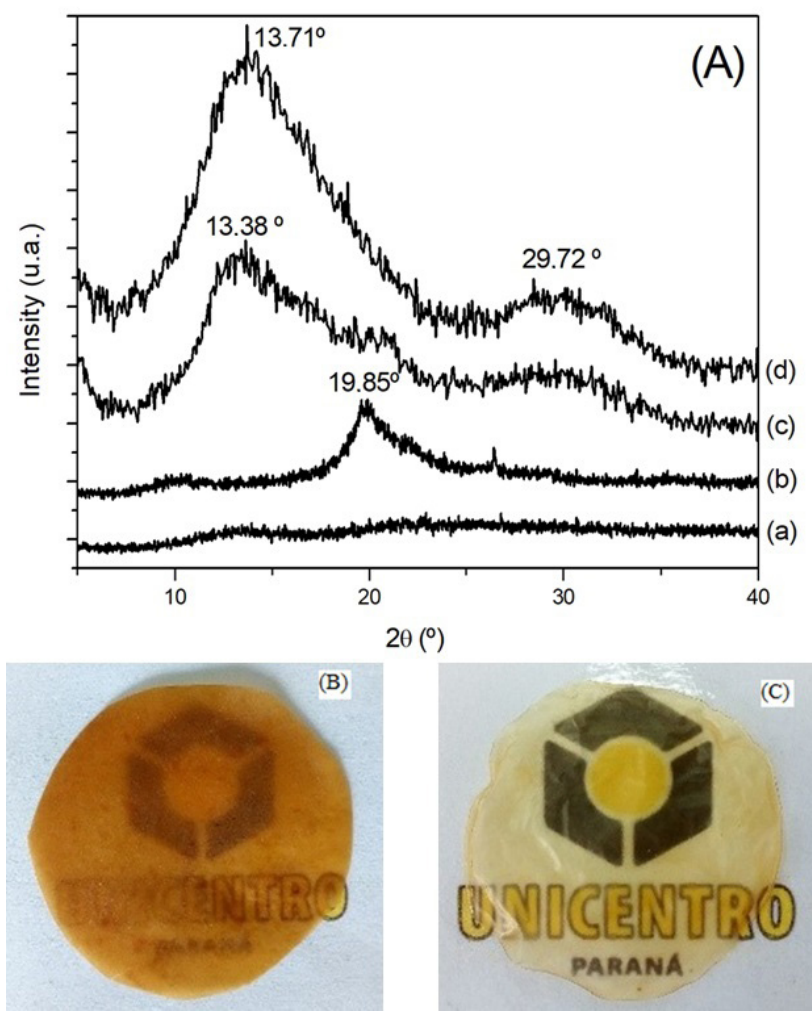

Figure 5. X-ray patterns diffractograms of the polymers (a) alginate, (b) chitosan, (c) chitosan/alginate membrane without cross-linker and (d) chitosan/alginate membrane with cross-linker. Image (B) without cross-linker chitosan/alginate membrane and (C) cross-linked chitosan/alginate membrane - HM.
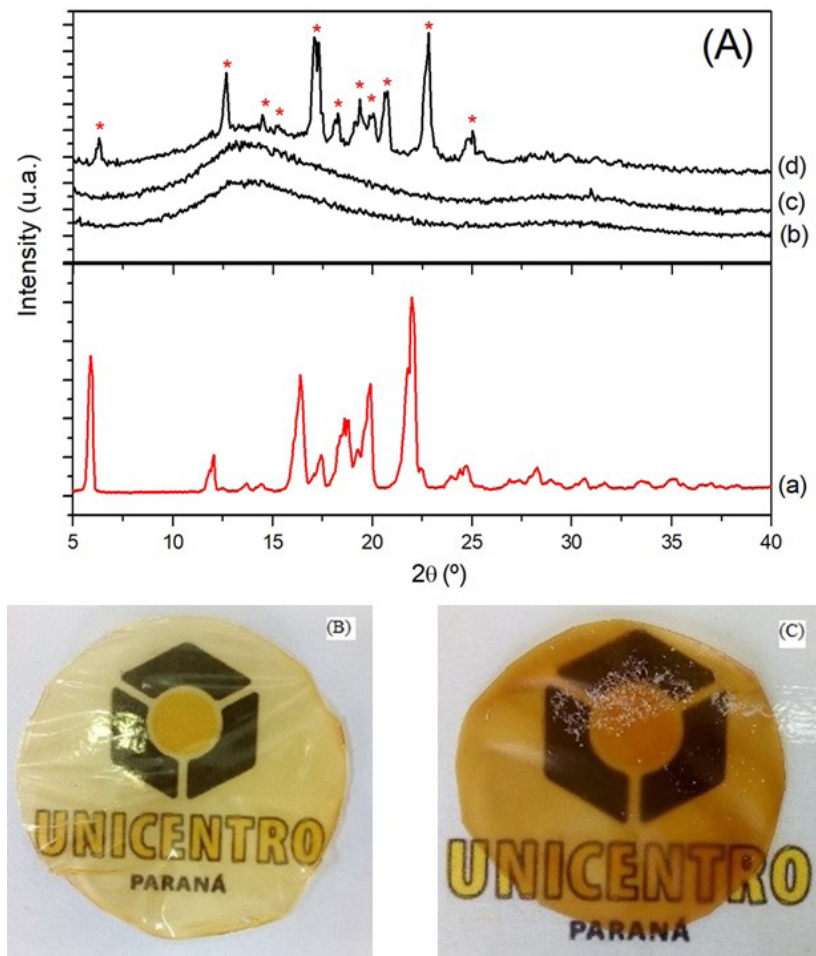

Figure 6. X-ray diffractograms patterns (A) of (a) ibuprofen, and chitosan/alginate membranes containing (b) HM/Zn $2 \mathrm{Al}-\mathrm{IBU}$, (c) HM/ $\mathrm{Zn}_{3} \mathrm{Al}-\mathrm{IBU}$ and (d) Ibuprofen. Image (B) chitosan/alginate membrane containing $\mathrm{HM} / \mathrm{Zn}_{2} \mathrm{Al}-\mathrm{IBU}$ and (C) chitosan/alginate membrane containing Ibuprofen - HM/IBU. 
presence of the characteristic peaks for LDHs, indicating that there was good load dispersion $(0.006 \mathrm{~g}$ Ibuprofen or $\mathrm{LDH}$ ) and/or exfoliation of the layered structure (Figure 6B).

The infrared spectra of membranes are shown in Figure 7, as well as the infrared spectrum of Ibuprofen (Figure 7a) for comparison of characteristic bands of the drug. The broadband in the region of $3300 \mathrm{~cm}^{-1}$ (Figure $7 \mathrm{~b}-\mathrm{e}$ ) is related to the $\mathrm{O}-\mathrm{H}$ link stretching present in the chitosan polymeric structure, the alginate, and N-H stretching from the amine group of the chitosan polymeric structure. The band at approximately $1590 \mathrm{~cm}^{-1}$ (Figure 7b, d, e) is related to the angular deformation of the N-H group of characteristic chitosan amines. The band at approximately $1395-1400 \mathrm{~cm}^{-1}$ (Figure $7 \mathrm{~b}, \mathrm{~d}, \mathrm{e}$ ) is related to the angular deformation of the $\mathrm{C}-\mathrm{H}$ aliphatic structural polymeric network. Furthermore, the bands in approximately 1025 and $1092 \mathrm{~cm}^{-1}$ (Figure 7b-e) are characteristic of the stretch of the C-O-C group of polysaccharides ${ }^{36}$.

In Figure $7 \mathrm{c}$, the band at approximately $1736 \mathrm{~cm}^{-1}\left(^{*}\right)$ refers to the stretch of group $\mathrm{C}=\mathrm{O}$ for carboxylic acids characteristic of ibuprofen crystallized on the membrane surface, as can be seen in Figure 6D. Moreover, the second band at approximately $1633 \mathrm{~cm}^{-1}\left(^{*}\right)$ refers to the angular deformation mode in the N-H group of amines ${ }^{35}$. All the vibrational modes observed in Figure 7 are summarized in Table S2 (supplementary material).

\subsection{In vitro release tests}

Through the analytical curves presented in Figure 8 (from 0.001 to $0.01 \mathrm{gL}^{-1}$ ), the linear correlation coefficients found were 0.99701 and 0.99928 for the release media in water and PBS, respectively. The absorption band at $222 \mathrm{~nm}$ was used to monitor the release tests, as this band is related to the transition $\pi \rightarrow \pi^{*}$ of the benzene ring replaced by the $\mathrm{COOH}$ group $^{37}$.

Statistical tests were performed in triplicates for each analytical curve so that the absorbance data for each analytical curve were normal and presented a p-value $>90 \%$ with a $95 \%$ significance level. That is, the probability of the absorbance results for each triplicate was equal $>90 \%$.

To verify if the absorbance data were significant for the construction of analytical curves, Pearson's Chi-square statistical test was performed. Presenting values of $\chi^{2}$ of 0.0027 and 0.0016 , which relates the relationship between the observed results and the expected results for the model, as the value of $\chi^{2}$ obtained $\left(\chi^{2}<0.003\right)$ was lower than the tabulated value for the $95 \%$ significance level $\left(\chi^{2}=30.144\right)$, that is, no statistical difference between the results obtained and the results expected by the model. Being the $\mathrm{p}$-value equal to 1.0000 for the curves in the release medium of water and PBS, respectively, the probability of absorbance data being applied to this model is $100 \%$. However, the linear correlation coefficients are $<0.9998$. The t-student and Chi-square tests for each analytical curve are presented in Table 2.

Figure 9 shows release curves for LDHs in water and PBS release media. For the LDHs in water release media (Figure 9a), it can be observed that in only $10 \mathrm{~min}$ the free ibuprofen ( ) solubilized approximately $47 \%$, and for LDHs $(\bullet$ and $\boldsymbol{\Delta}$ ) there was the release of 29 and $36 \%$ respectively of the drug to the media. The total solubilization of free ibuprofen occurs rapidly in only $40 \mathrm{~min}$, and for the LDHs, the full release of the drug occurs in approximately $5760 \mathrm{~min}$ (4 days) for both LDHs.

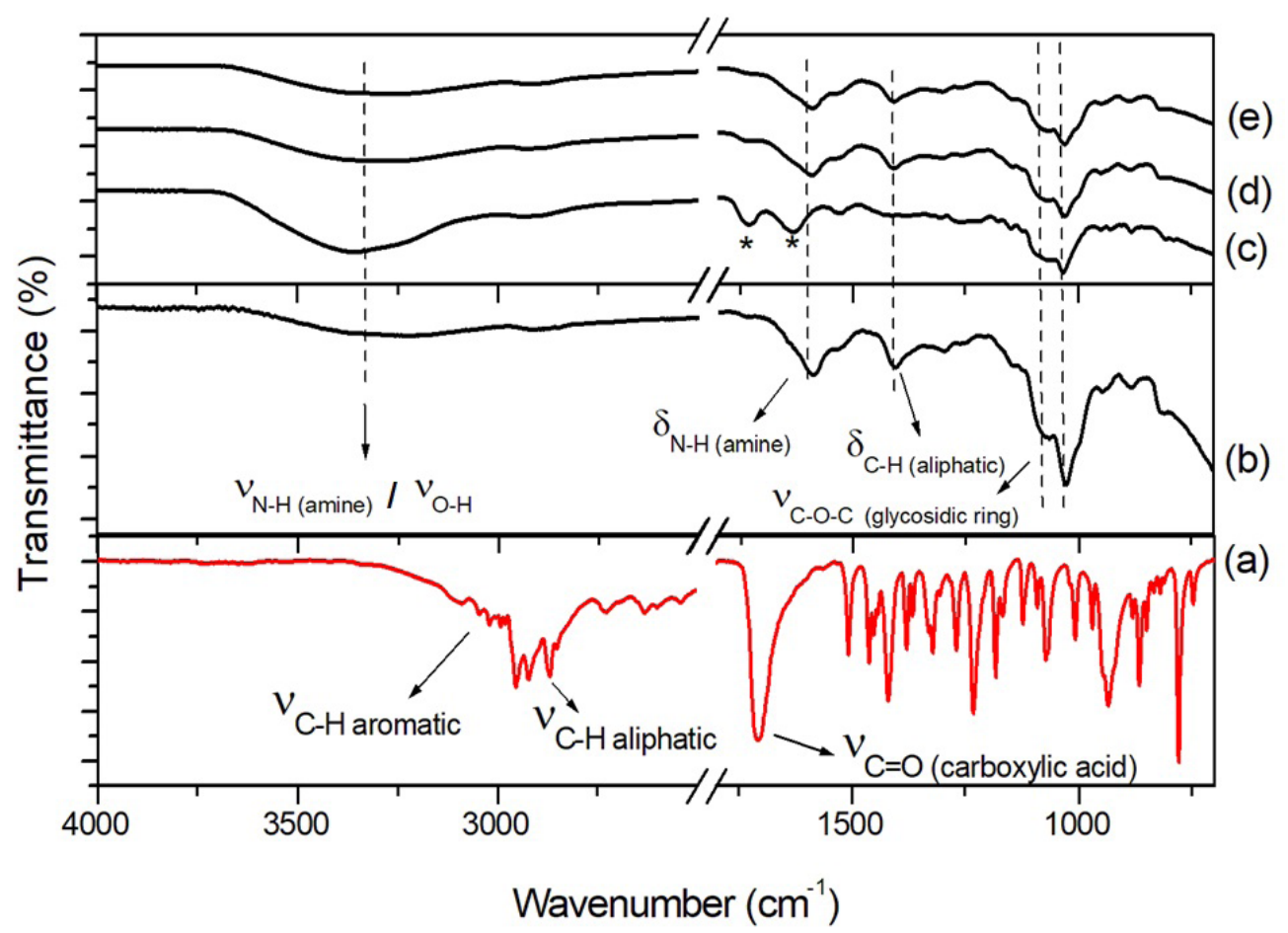

Figure 7. Infrared spectra for (a) Ibuprofen, (b) HM, (c) HM/IBU, (d) HM/Zn ${ }_{2} \mathrm{Al}-\mathrm{IBU}$ and (e) $\mathrm{HM} / \mathrm{Zn}_{3} \mathrm{Al}-\mathrm{IBU}$. 

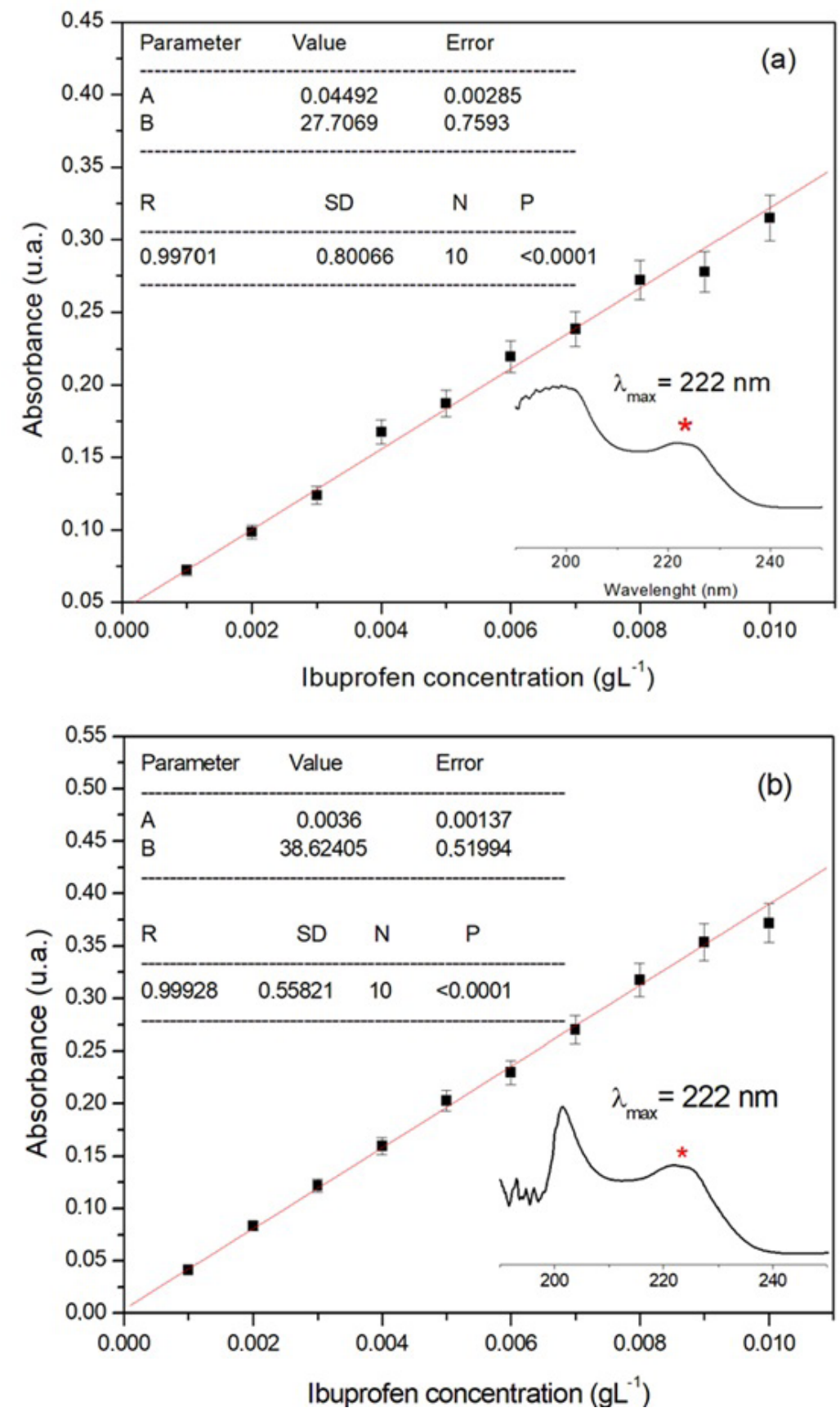

Figure 8. Analytical curves used in in vitro release tests for the quantification of ibuprofen in release medium (a) water and (b) PBS. Inset: Spectra of absorption of ibuprofen in each medium.

Regarding the PBS release tests (Figure 9b) the free ibuprofen (๘) quickly solubilizes completely in only 10 min. In this same period, the LDHs $(\bullet$ and $\mathbf{\Delta})$ released 56 and $67 \%$ of the drug to the medium, and the full release of the drug occurred in $1440 \mathrm{~min}$ (12 hours) and $5760 \mathrm{~min}$ (4 days), respectively.

Normally it would expect the $\mathrm{Zn}_{2} \mathrm{Al}-\mathrm{IBU}$ to have a faster release profile (higher drug release in a shorter time) when compared to the $\mathrm{Zn}_{3} \mathrm{Al}-\mathrm{IBU}$ independent of the release medium, due to the lower $\mathrm{M}^{2+} / \mathrm{M}^{3+}$ ratio allocate more anion in the interlayer space, because the amount of intercalated anion is stoichiometrically related to the $\mathrm{M}^{3+}$ ratio in the layered structure. However, it is observed that the $\mathrm{Zn}_{3} \mathrm{Al}-\mathrm{IBU}$ had a higher release profile initially; this effect is explained through the general formulas calculated experimentally and the X-ray diffractograms (Figure 1), indicating the presence of the crystallized free drug in the samples. Due to the weak interaction of these crystals with the layered structure, the initial release occurs quickly (Burst effect) ${ }^{38}$. 
Table 2. Statistical results for the analytical curves in water and PBS release medium with $95 \%$ significance level.

\begin{tabular}{ccc}
\hline Release medium for the analytical curve & Water & PBS \\
\hline \multirow{2}{*}{ Test t-student } & $\mathrm{t}$-value $=0.0603$ & $\mathrm{t}$-value $=0.0546$ \\
\cline { 2 - 3 } & $\mathrm{p}$-value $=0.9469$ & $\mathrm{p}$-value $=0.9570$ \\
\cline { 2 - 3 } Test $\chi^{2}$ de Pearson & $\chi^{2}=0.0027$ & $\chi^{2}=0.0016$ \\
\cline { 2 - 3 } & $\mathrm{p}=1.0000$ & $\mathrm{p}=1.0000$ \\
\hline
\end{tabular}

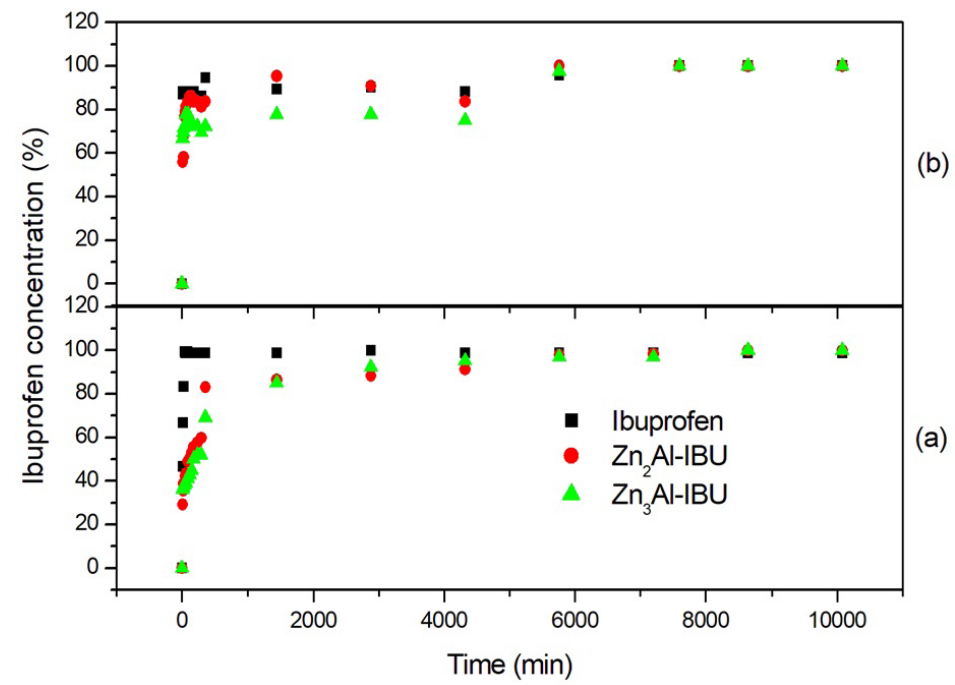

Figure 9. Solubility and release curves for Ibuprofen and LDHs in (a) water and (b) PBS.

Regarding in vitro release tests for LDHs in PBS release medium, it was observed that the samples presented in this work (up to $90 \%$ in $10000 \mathrm{~min}$ ) had a lower release rate of ibuprofen when compared to the literature. According to Ambrogi et al. ${ }^{35}$ the total of $60 \%$ release of the ibuprofen was only in 100 min using MgAl-LDH intercalated with ibuprofen. In other hand, in Yousefi et al. ${ }^{39}$ study, a magnetic Fe3O4@LDH containing ibuprofen was 92\% of maximum release in $72 \mathrm{~h}$. The in vitro ibuprofen release from Ibup$\mathrm{Zn}-\mathrm{Ti}-\mathrm{LDH}$ in Djaballah et al. ${ }^{40}$ study was up to $90 \%$ in $1500 \mathrm{~min}$. In this manner, the LDHs synthesized in this work release more slowly than compared to the LDHs synthesized by Ambriogi et al. ${ }^{35}$.

The kinetic analysis by the Weibull model (Equation 3) was the model that best fit the rate of release of LDHs in water, which expresses the cumulative fraction of the drug $(\mathrm{m})$ in the middle as a function of time $(\mathrm{t})$.

$m=\exp \left[-\frac{t-T_{i}}{a}\right]^{b}$

$\log [-\ln (1-m)]=b \log \left(t-T_{i}\right)-\log a$

Thus, the parameter $a$ defines the time scale of the process, the parameter $T_{i}$ represents the time interval before the beginning of the dissolution or release process (in most cases it is equal to zero), and the parameter $b$ that characterizes the curve as being exponential $(b=1)$, sigmoid $(b>1)$ or parabolic $(b<1)$. This kinetic model can be linearized (Equation 4), where the parameter $b$ is found through the angular coefficient of the line obtained.

This model is often used to describe the release speed from an unsolvable matrix system. This model indicates a lower contribution by diffusion to the drug release process and a higher contribution by dissolution ${ }^{37}$.

Thus, the linear correlation coefficients obtained for this model were 0.9979 and 0.9497 for LDHs with a 2:1 and 3:1 molar ratio, respectively (Figure 10a-b). Although the linear correlation coefficient for the $3: 1 \mathrm{LDH}$ is lower than the $2: 1 \mathrm{LDH}$, both have p-value equal to 1.000 and $\chi^{2}$ equal to $0.000\left(\chi^{2}\right.$ tabulated $\left.=28.869\right)$ obtained through the Chi-square statistical test, indicating that there is no statistical difference between the results obtained with the results expected by the model and that the probability of the Weibull kinetic model is $100 \%$ applicable for both LDHs, characterizing the release mechanism mainly by the process of dissolution of the LDHs in the medium.

Regarding the values of parameter $b$ found, in both LDHs, the value of $b<1$, which characterizes the release curve as being parabolic, indicating that in some time, the concentration of the drug released in the middle begins to decline until it reaches zero ${ }^{38}$.

The kinetic analysis by the Baker-Lonsdale's model (Equation 5) was the model that best fitted the release rate of LDHs in PBS, which expresses the amount of the drug released in the middle $(\mathrm{Mt})$ as a function of time $(\mathrm{t})$.

$\frac{3}{2}\left[1-\left(1-\frac{M_{t}}{M_{\infty}}\right)^{2 / 3}\right]-\frac{M_{t}}{M_{\infty}}=k t$ 

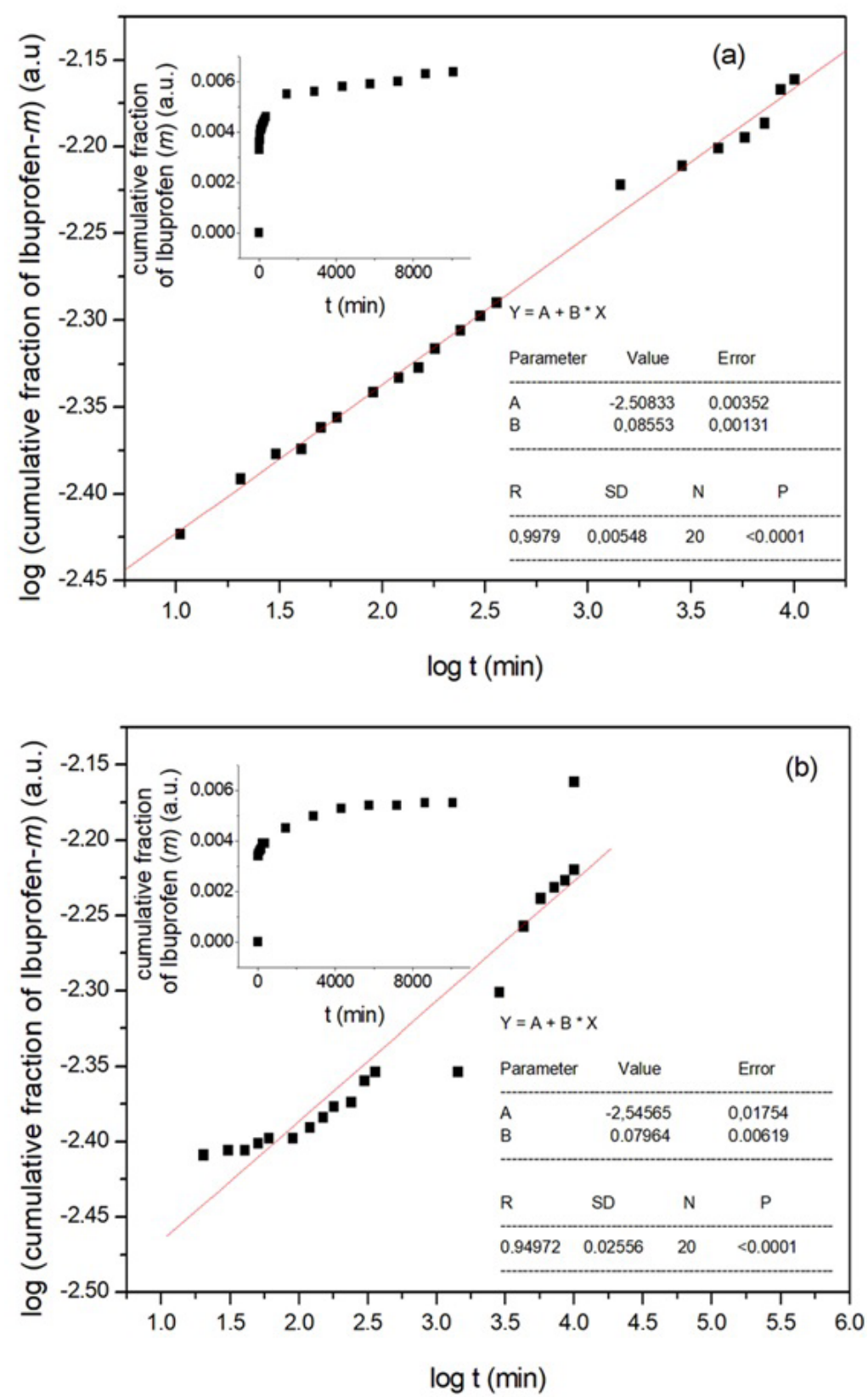

Figure 10. Weibull linearized kinetic models for the HDLs (a) $\mathrm{Zn}_{2} \mathrm{Al}-\mathrm{IBU}$ and (b) $\mathrm{Zn}_{3} \mathrm{Al}-\mathrm{IBU}$ water release. Inset: respective non-linear kinetic models.

This model is used to describe the release of the drug from a spherical and homogeneous matrix. Thus, $M$ is the amount of drug released at time t, $M_{\infty}$ the amount of drug released at an infinite time and $\mathrm{k}$ the constant of drug release (equal to the angular coefficient of the straight line $)^{41}$.

Thus, the linear correlation coefficients obtained for this model were 0.9789 and 0.9927 for LDHs with a $2: 1$ and $3: 1$ molar ratio, respectively (Figure 11a-b). Through the Chisquare statistical test, the $\mathrm{p}$-values were 1.000 and $\chi^{2}<0.05$ $\left(\chi^{2}\right.$ tabulated $\left.=23.685\right)$ for both LDHs, indicating that there is no statistical difference between the results obtained and the results expected by the model and that the probability of the Baker-Lonsdale kinetic model is $100 \%$ applicable for these samples, indicating that the release mechanism occurs through the process of drug diffusion through the pores of the matrix.

Thus, the values of the drug release constants $(\mathrm{k})$ were $4.41234 \times 10^{-5}$ and $4.36266 \times 10^{-5}$. Considering the error attributed to the constants, the constants for both LDHs are practically the same, but observing the graphs of the drug release rate as a function of time (Insets in Figure $12 \mathrm{a}-\mathrm{b}$ ) the drug release rate as a function of time was significantly higher for LDH with a 2:1 molar ratio, which can be attributed to the presence of recrystallized ibuprofen in the sample. 

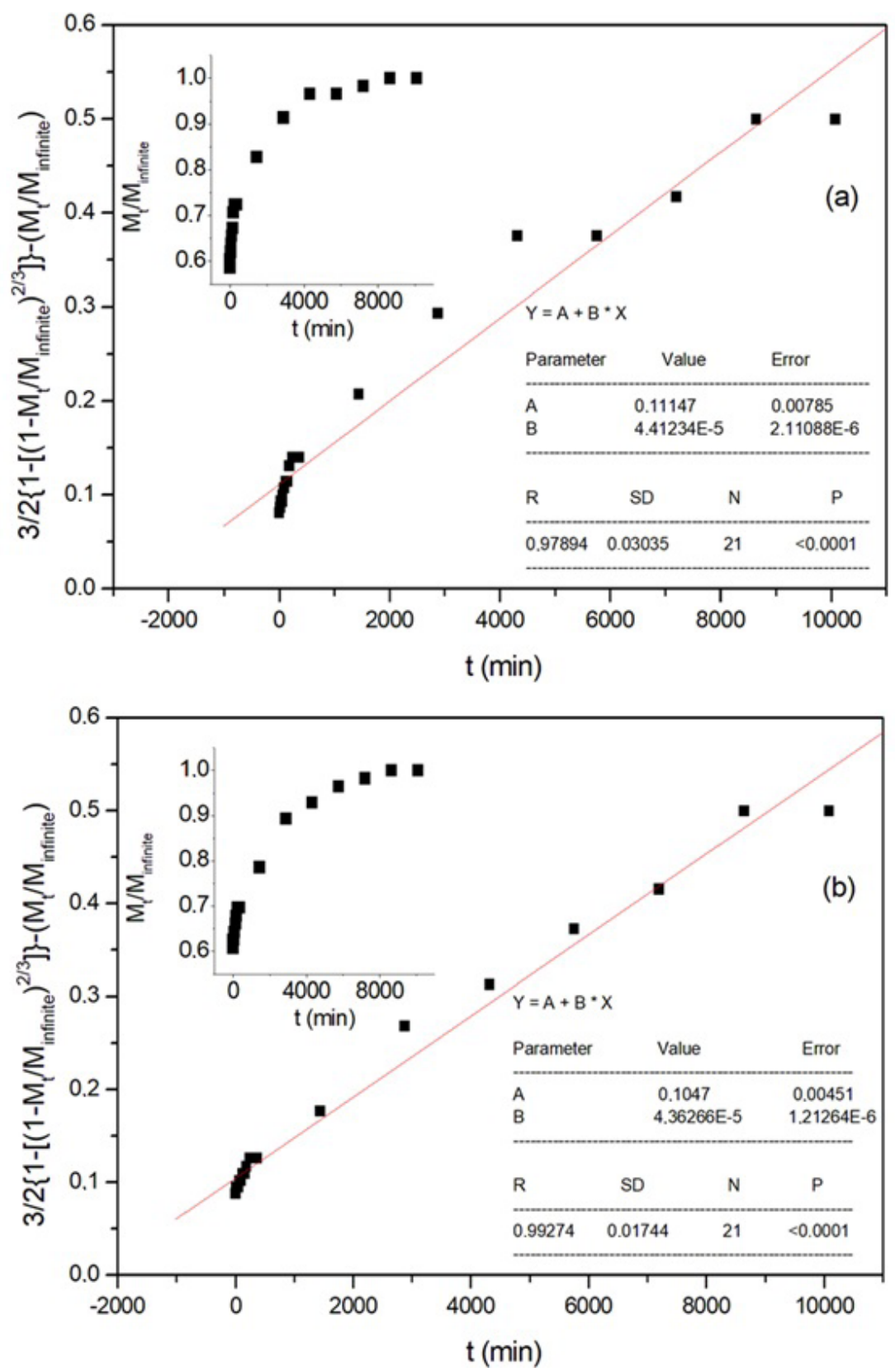

Figure 11. Linearized Baker-Lonsdale kinetic models for the (a) $\mathrm{Zn}_{2} \mathrm{Al}-\mathrm{IBU}$ and (b) $\mathrm{Zn}_{3} \mathrm{Al}-\mathrm{IBU}$ release in PBS. Inset: respective nonlinear kinetic models.

The presence of phosphate anions in the solution was the determining factor in applying the chosen kinetic model. Thus, assuming that the release process involved is related to the ionic exchange between the ion Ibuprofenate intercalated with the phosphate ion present in the release medium. As the experiments were performed under Sink conditions, it was not possible to recover the samples after the release tests so that the ionic exchange suffered by the LDHs could be proved ${ }^{35}$.

Release curves for the membranes containing the drug and the synthesized LDHs are presented in Figure 10. For the membranes in water release medium (Figure 12a), for both membranes, the release of the drug to the medium started only in $2880 \mathrm{~min}$ ( 24 hours), presenting release percentages of approximately 1,10 , and $12 \%$ and the maximum release of the drug was 3,13 , and $17 \%$ for the membranes $\mathrm{MH} /$ $\mathrm{IBU}(\boldsymbol{\bullet}), \mathrm{MH} / \mathrm{Zn}_{2} \mathrm{Al}-\mathrm{IBU}(\bullet)$ and $\mathrm{MH} / \mathrm{Zn}_{3} \mathrm{Al}-\mathrm{IBU}(\boldsymbol{\Delta})$, respectively. For the membranes in the middle of PBS release (Figure 12b), for both membranes the release of the drug started only in 720 min (12 hours), presenting release percentages of approximately 2, 15 and $19 \%$ and the maximum release of the drug was 5, 20 and $26 \%$ for the $\mathrm{MH} / \mathrm{IBU}(\bullet), \mathrm{MH} / \mathrm{Zn}_{2} \mathrm{Al}-\mathrm{IBU}(\bullet)$ and $\mathrm{MH} / \mathrm{Zn}_{3} \mathrm{Al}-\mathrm{IBU}$ $(\boldsymbol{\Delta})$, respectively. 


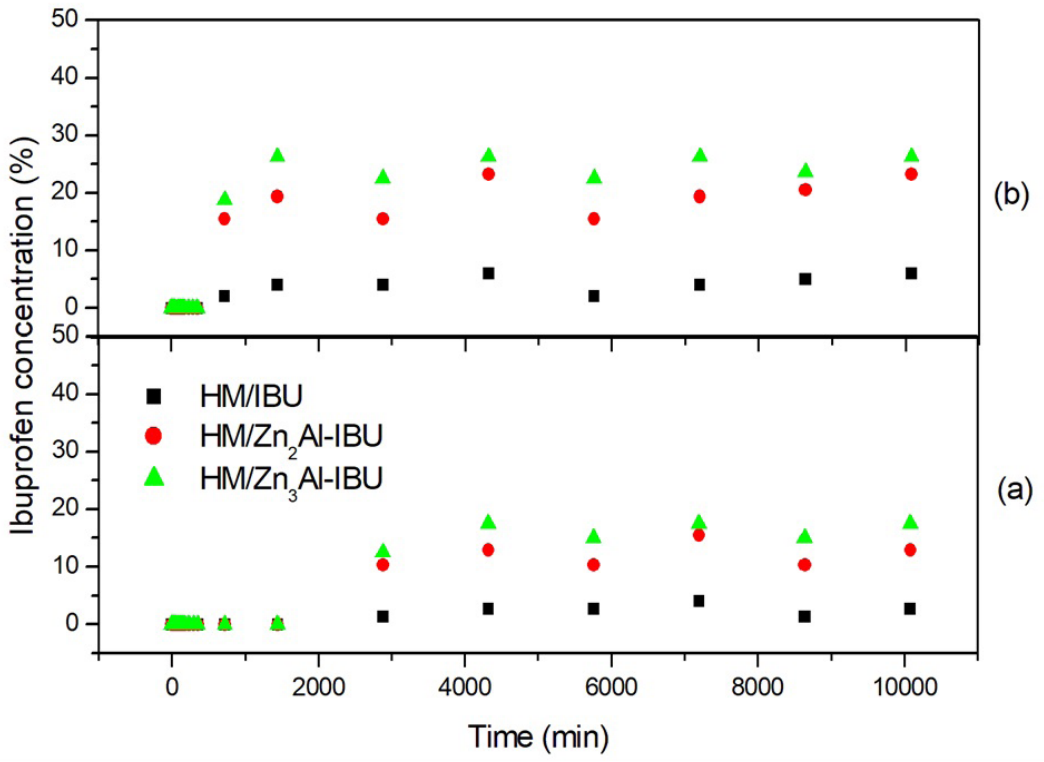

Figure 12. Release curves for HM/IBU and HM/LDHs membranes in (a) water and (b) PBS.

In comparison, the release curves for LDHs (Figure 12) with the release curves for membranes (Figure 10), the membrane that obtained the highest release rate was the $\mathrm{MH} / \mathrm{Zn}_{3} \mathrm{Al}-\mathrm{IBU}$, contrary effect when observed with free LDHs. This effect may be related to the greater destabilization of the polymeric network suffered by the addition of this LDH, favoring membrane disaggregation and achieving a higher release rate of the drug to the medium. For the membranes in PBS release medium (Figure 12b), the release rate was higher when compared to the water release curve (Figure 12a) due to the presence of phosphate anions that favored membrane disaggregation and thus the higher release rate ${ }^{35}$.

For membranes containing only Ibuprofen, $\mathrm{MH} / \mathrm{IBU}$ (घ), the lowest release rate for these membranes is due to the elimination in the immersion stages of large quantities of the crystallized drug on the surface of the membranes, thus reducing the total concentration of the drug in the membranes.

Regarding the kinetic study for hybrid membranes, no model was compatible with describing the membrane release profile, where the values of $\mathrm{R}$ were $<0.5$. This is due to the fact that the concentration of the drug released in the medium did not reach at least $50 \%$ and did not enter into equilibrium, these factors being determinants for the application of known kinetic models of release. Thus, a more extended time is needed for the release study for these samples ${ }^{42}$.

\section{Conclusions}

The Ibuprofen materials with the layered double hydroxides of $\mathrm{Zn} / \mathrm{Al}$ with the ratios of the metals di and trivalent of 2:1 and 3:1 were easily synthesized by the co-precipitation method under constant $\mathrm{pH}$. After the cross-linking agent immersion processes, hybrid chitosan/alginate membranes differed from hybrid membranes that did not undergo this process, i.e., immersions contributed to a higher organization of the polymeric networks as indicated by XRD results and visibly higher crystallinity and translucency of the membranes. In the in vitro release tests performed on PBS release media, it was observed that only LDHs release profile was linear and slower when compared only with the free drug. The proposed mechanism for releasing the drug in these materials is the Weibull kinetic model for the water release media and the Baker-Lonsdale kinetic model for the PBS release media. In the membrane release tests, it was possible to observe that a more extended time would be required to perform these tests due to the very low release rate. However, these correlations obtained were useful to predict and optimize the behavior of these systems for future applications in the administration of drugs based on LDHs and chitosan/alginate membranes.

\section{Acknowledgments}

This study was financed in part by the Coordenação de Aperfeiçoamento de Pessoal de Nível Superior - Brasil (CAPES) - Finance Code 001, and the Conselho Nacional de Desenvolvimento Científico e Tecnológico (CNPq) [grant number 455906/2014-9].

\section{References}

1. Wang W, Yeung KWK. Bone grafts and biomaterials substitutes for bone defect repair: a review. Bioact Mater. 2017;2(4):224 47.

2. Lin X, Ge J, Wei D, Liu C, Tan L, Yang H, et al. Surface degradation-enabled osseointegrative, angiogenic and antiinfective properties of magnesium-modified acrylic bone cement. J Orthop Translat. 2019;17:121-32.

3. Lobb DC, DeGeorge BR Jr, Chhabra AB. Bone graft substitutes: current concepts and future expectations. J Hand Surg Am. 2019;44(6):497-505.e2.

4. Jones A-AD 3rd, Xie Z, Webster TJ. A hierarchical integration pyramid to increase translation of biomaterials based on recent successes in multiscale. Current Opinion Biomedical Engineering. 2019;10:89-96 
5. García-Gareta E, Coathup MJ, Blunn GW. Osteoinduction of bone grafting materials for bone repair and regeneration. Bone. 2015;81:112-21.

6. Kim SS, Sun Park M, Jeon O, Yong Choi C, Kim BS. Poly(lactideco-glicolide)/hydroxyapatite composite scaffolds for bone tissue engineering. Biomaterials. 2016;27(8):1399-409.

7. Prasadh S, Wong RCW. Unraveling the mechanical strength of biomaterials used as a bone scaffold in oral and maxillofacial defects. Oral Sci Int. 2018;15(2):48-55.

8. Zhang Q, Wu W, Qian C, Xiao W, Zhu H, Guo J, et al. Advanced biomaterials for repairing and reconstruction of mandibular defects. Mater Sci Eng C. 2019;103:109858.

9. Thrivikraman G, Athirasala A, Twohig C, Boda SK, Bertassoni LE. Biomaterials for craniofacial bone regeneration. Dent Clin North Am. 2017;61(4):835-56.

10. Devgan S, Sidhu SS. Evolution of surface modification trends in bone related biomaterials: A review. Mater Chem Phys. 2019;233:68-78.

11. Zeng Y, Hoque J, Varghese S. Biomaterial-assisted local and systemic delivery of bioactive agents for bone repair. Acta Biomater. 2019;93:152-68.

12. Kohli N, Ho S, Brown SJ, Sawadkar P, Sharma V, Snow M, et al. Bone remodelling in vitro: where are we headed?-A review on the current understanding of physiological bone remodelling and inflammation and the strategies for testing biomaterial in vitro. Bone. 2018;110:38-46.

13. Theken KN. Viability in analgesic response to non-steroidal anti-inflammatory drugs. Prostaglandins Other Lipid Mediat. 2018;139:63-70

14. Aznar-Arasa L, Harutunian K, Figueiredo R, Valmaseda-Castellón E, Gay-Escoda C. Effect of preoperative Ibuprofen on pain and swelling after lower third molar removal: a randomized controlled trial. Int J Oral Maxillofac Surg. 2012;41(8):1005-9.

15. Di Lenarda R, Cadenaro M, Stacchi C. Paresthesia of the mental nerve induced by periapical infection: A case report. Oral Surg Oral Med Oral Pathol Oral Radiol Endod. 2000;90(6):746-9.

16. Gautam R, Jachak SM. Recent developments in anti-inflammatory natural products. Med Res Rev. 2009;29(5):767-820.

17. Ay A, Zumreoglu-Karan B, Temel A, Rives V. Bioinorganic magnetic core-shell nanocomposites carrying antiarthritic agentes: intercalation of Ibuprofen and glucuronic acid into $\mathrm{Mg}$-Al-layered double hydroxides supported on magnesium ferrite. Inorg Chem. 2009;48(18):8871-7.

18. Del Hoyo D. Layered double hydroxides and human health: an overview. Appl Clay Sci. 2007;36(1-3):103-21.

19. Bi X, Zhang H, Dou L. Layered double hydroxide-based nanocarriers for drug delivery. Pharmaceutics. 2014;6(2):298332.

20. Rives V, Del Arco M, Martín C. Layered double hydroxides as drug carriers and for controlled release of non-steroidal antiinflammatory drugs (NSAIDs): a review. J Control Release. 2013;169(1-2):28-39.

21. Chatterjee A, Bharadiya P, Hansora D. Layered double hydroxide based bionanocomposites. Appl Clay Sci. 2019;177:19-36.

22. Mishra G, Dash B, Pandey S. Layered double hydroxides: a brief review from fundamentals to application as evolving biomaterials. Appl Clay Sci. 2018;153:172-86.

23. Li J, Ying S, Ren H, Dai J, Zhang L, Liang L, et al. Molecular dynamics study on the encapsulation and release of anti-cancer drug doxorubicin by chitosan. Int J Pharm. 2020;580:119241.

24. Laipan M, Xiang L, Yu J, Martin BR, Zhu R, Zhu J, et al. Layered intercalation compounds: mechanisms, new methodologies, and advanced applications. Prog Mater Sci. 2019;109:100631.

25. Wang Y, Shen S, Hu T, Williams GR, Bian Y, Feng B, et al. Layered double hydroxide modified bone cement promoting osseointegration via multiple osteogenic signal pathways. ACS Nano. 2021;15(6):9732-45.
26. Liu P, Li M, Yu H, Fang H, Yin J, Zhu D, et al. Biphasic CK2.1-coated $\beta$-glycerophosphate chitosan/LL37-modified layered double hydroxide chitosan composite scaffolds enhance coordinated hyaline cartilage and subchondral bone regeneration. Chem Eng J. 2021;418:129531.

27. Shokrolahi F, Latif F, Shokrollahi P, Farahmandghavi F, Shokrollahi S. Engineering atorvastatin loaded $\mathrm{Mg}-\mathrm{Mn} / \mathrm{LDH}$ nano particles and their composite with PLGA for bone tissue applications. Int J Pharm. 2021;606:120901.

28. Kim MH, Hur W, Choi G, Min HS, Choi TH, Choy YB, et al. Theranostic bioabsorbable bone fixation plate with druglayered double hydroxide nanohybrids. Adv Healthc Mater. 2016;5(21):2765-75.

29. Venezuela J, Dargusch MS. The influence of alloying and fabrication techniques on the mechanical properties, biodegradability and biovompatibility of zinc: a comprehensive review. Acta Biomater. 2019;87:1-40.

30. Rudnev VS, Lukiyanchuk IV, Vasilyeva MS, Medkov MA, Adigamova MV, Sergienko VI. Aluminum- and titaniumsupported plasma electrolytic multicomponent coatings with magnetic, catalytic, biocide or biocompatible properties. Surf Coat Tech. 2016;307:1219-35.

31. Saha S, Ray S, Acharya R, Chatterjee TK, Chakraborty J. Magnesium, zinc and calcium aluminium layered double hydroxide-drug nanohybrids: a comprehensive study. Appl Clay Sci. 2017;135:493-509.

32. Gordino CR, Barbosa CAS, Da Costa Ferreira AM, Constantino VRL, de Silva D. Immobilization of Ibuprofen and copperibuprofen drugs on layered double hydroxides. J Pharm Sci. 2005;94(5):1135-48.

33. Rojas R, Linck YG, Cuffini SL, Monti GA, Giacomelli CE. Structural and physicochemical aspects of drug release from layered double hydroxides and layered hydroxides salts. Appl Clay Sci. 2015;109-110:119-26.

34. Misol A, Labajos FM, Morato A, Rives V. Synthesis of Zn, Al layered double hydroxides in the presence of amines. Appl Clay Sci. 2020;189:105539.

35. Ambrogi V, Fardella G, Grandolini G, Perioli L. Intercalation compounds of hydrotalcite-like anionic clays with antiinflammatory agents - I Intercalation and in vitro release of Ibuprofen. Int J Pharm. 2001;220(1-2):23-32.

36. Parello ML, Rojas R, Giacomelli CE. Dissolution kinects and mechanism of $\mathrm{Mg}-\mathrm{Al}$ layered double hydroxides: a simple approach to describe drug release in acid media. J Colloid Interface Sci. 2010;351(1):134-9.

37. Ibitoye EB, Lokman IH, Hezmee MNM, Goh YM, Zuki ABZ, Jimoh AA. Extraction and physicochemical characterization of chitin and chitosan solated from house cricket. Biomed Mater. 2018;13(2):025009.

38. Gunawan P, Xu R. Direct control of drug release behavior from layered double hydroxides throught particle interactions. J Pharm Sci. 2008;97(10):4367-78.

39. Yousefi V, Tarhriz V, Eyvazi S, Dilmaghani A. Synthesis and application of magnetic@layered double hydroxide as an antiinflammatory drugs nanocarrier. J Nanobiotechnology. 2020;18(1):155.

40. Djaballah R, Bentouami A, Benhamou A, Boury B, Elandaloussi $\mathrm{EH}$. The use of $\mathrm{Zn}$-Ti layered double hydroxide interlayer spacing property for low-loading drug and low-dose therapy. Synthesis, characterization and release kinetics study. J Alloys Compd. 2018;739:559-67.

41. Lu T, ten Hagen TLM. A novel kinect model to describe the ultra-fast triggered release of thermosensitive liposomal drug delivery. J Control Release. 2020;324:669-78.

42. Choina J, Kosslick H, Fischer C, Flechsig G-U, Frunza L, Schulz A. Photocatalytic decomposition of pharmaceutical ibuprofen pollutions in water over titania catalyst. Appl Catal B. 2013;129:589-98. 


\section{Supplementary material}

The following online material is available for this article:

Table S1-Vibrational modes for the bands observed in the infrared spectra for (a) Ibuprofen and (b,c) LDHs.

Table S2 - Vibrational modes for the bands observed in the infrared spectra for (a) MH, (b) MH-IBU and (c, d) MH-LDHs.

Figure S1 - Scheme of membrane synthesis. 